\title{
General Synthesis of Cyclopropanols via Organometallic Addition to 1- Sulfonylcyclopropanols as Cyclopropanone Precursors
}

\author{
Roger Machín Rivera, Yujin Jang, Christopher M. Poteat and Vincent N. G. Lindsay* \\ Department of Chemistry, North Carolina State University, 2620 Yarbrough Drive, Raleigh, North Carolina 27695, United States
}

Supporting Information Placeholder

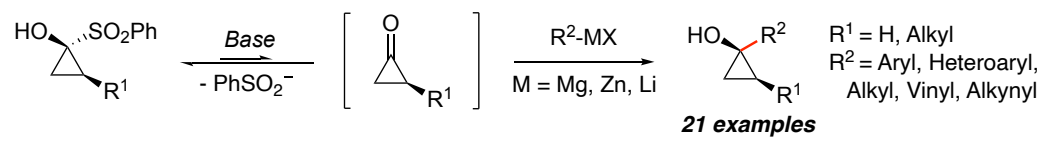

\begin{abstract}
The addition of organometallic reagents to ketones constitutes one of the most straightforward synthetic approaches to tertiary alcohols. However, due to the absence of a well-behaved class of cyclopropanone surrogates accessible in enantioenriched form, such a trivial synthetic disconnection has only received very little attention in the literature for the formation of tertiary cyclopropanols. In this work, we report a simple and high-yielding synthesis 1-substituted cyclopropanols via the addition of diverse organometallic reagents to 1phenylsulfonylcyclopropanols, acting here as in situ precursors of the corresponding cyclopropanones. The transformation is shown to be amenable to $\mathrm{sp}, \mathrm{sp}^{2}$ or $\mathrm{sp}^{3}$-hybridized organometallic C-nucleophiles under mild conditions, and the use of enantioenriched substrates led to highly diastereoselective additions and the formation of optically active cyclopropanols.
\end{abstract}

Cyclopropanols constitute versatile building blocks for the elaboration of complex natural products and pharmaceuticals. ${ }^{1,2}$ Particularly, extensive chemistry has been developed over the last decades by using the intrinsic propensity of cyclopropanols to act as homoenolate equivalents in the presence of a variety of transition metals and (pseudo)electrophiles. ${ }^{3}$ For example, the pluripotential of cyclopropanols was recently demonstrated via late-stage functionalization, affording different derivatives of Chlamydocin, a histone deacetylase inhibitor. ${ }^{4}$ Despite the obvious relevance of cyclopropanols in the construction of biologically relevant molecules, the development of novel and general methods for the formation of tertiary derivatives, ${ }^{5}$ leading to $\beta$-nucleophilic ketone equivalents, has remained scarce. ${ }^{6,7}$ The most conventional approaches to these compounds include the cyclopropanation of enols using carbenoid species (Scheme 1a) ${ }^{3 e, 8,9}$ or the Kulinkovich cyclopropanation of esters (Scheme $1 b),{ }^{10,11,12}$ both of which are rarely amenable to the formation of enantioenriched products and possess considerable limitations in terms of practicality and sustainability. ${ }^{13} \mathrm{~A}$ distinct approach, which consists of introducing the $C(1)$-substituent last via nucleophilic addition to a cyclopropanone surrogate, is not general mainly due to the absence of suitable precursors readily accessible in enantioenriched form (Scheme 1c). Indeed, as initially reported by Wasserman, ${ }^{14,15}$ cyclopropanone hemiketals can be used as substrates to afford tertiary cyclopropanols via equilibration to cyclopropanones and reaction with Grignard reagents, though these typically require harsh conditions to react and are not generally accessible in optically active form, ${ }^{16}$ precluding their general use for this purpose. Moreover, these same hemiketal reagents are also known to competitively equilibrate to $\beta$-nucleophilic esters in basic conditions, ${ }^{3,17}$ overall reducing the yield of desired cyclopropanol. On the other hand, the direct organometallic addition to the parent cyclopropanone itself is very rarely a viable approach, mainly due to the extreme kinetic instability and difficulty of preparation of such highly strained ketones, ${ }^{18}$ typically using ketenes and explosive diazomethane. ${ }^{19,20}$

Scheme 1. Common Approaches to Tertiary Cyclopropanols

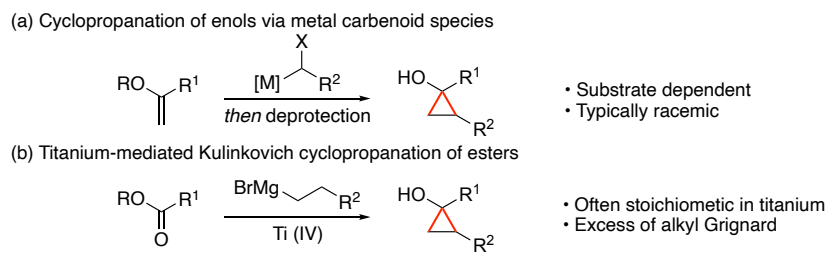

(c) Previous Work: Organometallic addition to hemiketal cyclopropanone equivalents

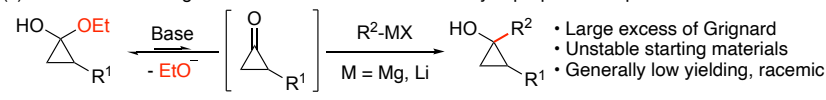

(d) This Work: Organometallic addition to 1-sulfonylcyclopropanols as cyclopropanone precursor

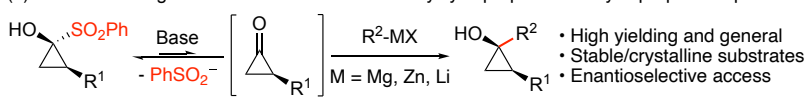

In 2008, Chen reported a new crystalline, bench stable and particularly well-behaved precursor of unsubstituted cyclopropanone, 1phenylsulfonylcyclopropanol. ${ }^{21}$ In our group, we recently reported a general enantioselective method allowing access to different substituted cyclopropanone precursors of this type, in two simple steps starting from readily available substrates. ${ }^{22}$ With general access to this new type of highly reactive cyclopropanone precursor now established, we envisioned that we could use them to access a wide variety of tertiary cyclopropanols. Herein, we report a simple and general high-yielding synthesis of 1-substituted cyclopropanols via the 
addition of diverse organometallic reagents to 1-phenylsulfonylcyclopropanol derivatives, acting here as in situ precursors of the corresponding cyclopropanones (Scheme 1d). To avoid the use of excess nucleophile, a variant using $\mathrm{MeMgBr}$ as a base to trigger the initial equilibration to cyclopropanone is also included, and the use of enantioenriched substituted derivatives is shown to afford optically active tertiary cyclopropanols in high yields and complete diastereoselectivity for the cis product.

Using cyclopropanone precursor 1a and p-methoxyphenylmagnesium bromide as model substrates, we first investigated various conditions to access tertiary cyclopropanol $2 \mathrm{a}$ (Table 1$)$. In such a situation, an excess of Grignard reagent ( $>2$ equiv) is required since one equivalent is initially consumed to deprotonate the hydroxyl group in 1a and trigger its equilibration to cyclopropanone. Surprisingly, while running the reaction at 0 or $-78{ }^{\circ} \mathrm{C}$ (entries 1-2) or using a short reaction time (entry 3 ) afforded complete consumption of $1 \mathbf{a}$, only small amounts of desired $2 \mathrm{a}$ could be isolated in pure form. Further analysis of the crude mixture revealed the presence of unseparable oligomers such as $\mathbf{3}$ as main side-products (Scheme 2), resulting from the addition of the tertiary alkoxide 2 ' initially produced to residual cyclopropanone species present in solution. As such an addition is reversible, warming the reaction to room temperature for a longer period of time eventually eliminated these undesired oligomers and offered reasonable yields of $2 \mathbf{a}$ (entry 4 ). A survey of various ethereal solvents revealed that THF and $t$-BuOMe both provided good yields of product (entries 4-6). ${ }^{23}$ Lowering the concentration (entry 7) or using a slight excess of nucleophile (entry 8) both improved the reaction efficiency, and combining this information offered an excellent isolated yield of 91\% (entry 9).

Table 1. Method A optimization: Grignard as sacrificial base

\begin{tabular}{|c|c|c|c|c|c|c|}
\hline entry & equiv & solvent & $\begin{array}{l}\text { temp. } \\
\left({ }^{\circ} \mathrm{C}\right)\end{array}$ & $\begin{array}{l}\text { conc. } \\
\text { (M) }\end{array}$ & $\begin{array}{l}\text { time } \\
\text { (h) }\end{array}$ & $\begin{array}{l}\text { yield } \\
(\%)^{a}\end{array}$ \\
\hline 1 & 2 & THF & 0 & 1.0 & 5 & $71^{b, c, d}$ \\
\hline 2 & 2 & THF & -78 & 1.0 & 5 & $\mathrm{ND}^{c, d}$ \\
\hline 3 & 2 & THF & 0 to $\mathrm{rt}$ & 1.0 & 2 & $62^{b, c}$ \\
\hline 4 & 2 & THF & 0 to rt & 1.0 & 5 & 75 \\
\hline 5 & 2 & $t$-BuOMe & 0 to rt & 1.0 & 5 & 78 \\
\hline 6 & 2 & $\mathrm{Et}_{2} \mathrm{O}$ & 0 to rt & 1.0 & 5 & 63 \\
\hline 7 & 2 & THF & 0 to rt & 0.10 & 5 & 86 \\
\hline 8 & 2.2 & THF & 0 to rt & 1.0 & 5 & 89 \\
\hline 9 & 2.2 & THF & 0 to rt & 0.10 & 5 & 91 \\
\hline
\end{tabular}

${ }^{a}$ Isolated yield on $0.25 \mathrm{mmol}$ scale unless otherwise noted. ${ }^{b}$ Yield determined by ${ }^{1} \mathrm{H}$ NMR using 1,3,5-trimethoxybenzene as standard. 2a could not be isolated due to the presence of unseparable dimeric prod-

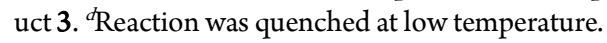

Scheme 2. Formation of undesired dimeric products 3

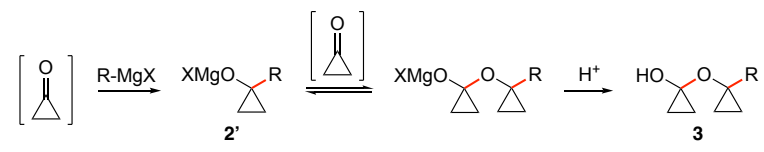

In an effort to avoid the use of excess Grignard reagent used in the reaction, we sought to evaluate external bases that would play the role of triggering equilibration to cyclopropanone. Indeed, especially for the construction of natural products or other complex molecules, the nucleophile could be valuable and should not be wasted in a simple deprotonation step. To do so, we evaluated different bases and initial temperatures that would promote such deprotonation while avoiding equilibration to unstable cyclopropanone until addition of the desired nucleophile (Table 2). While strong lithium and sodium bases led to extensive decomposition and polymerization likely due to the formation of free cyclopropanone in solution (entries 1-3), weaker bases such as $\mathrm{Et}_{3} \mathrm{~N}$ only afforded poor conversion (entry 4). In contrast, the use of a cheaper Grignard reagent $(\mathrm{MeMgBr})$ as initial base led to a more stable magnesium alkoxide intermediate that could be sustained at low temperature for longer periods of time, affording an optimal yield of $\mathbf{2} \mathbf{a}$ when added in substoichiometric amount at $-78^{\circ} \mathrm{C}$ and warmed to room temperature after the addition of the nucleophile (entries 5-7). Although ( $n$ $\mathrm{Bu})_{2} \mathrm{Mg}$ afforded a slightly higher yield (entry 8 ), $\mathrm{MeMgBr}$ was selected as ideal base for the method due to its lower price and increased functional group compatibility.

Table 2. Method B optimization: Grignard economy via the use of an external base

\begin{tabular}{lllll}
$\underset{1 \mathrm{a}}{{ }_{\text {entry }}^{\mathrm{HO}}}$ & base & equiv & temp $\left({ }^{\circ} \mathrm{C}\right)$ & yield $(\%)^{a}$ \\
\hline 1 & $\mathrm{LDA}$ & 1.0 & 0 & 10 \\
2 & $\mathrm{LDA}$ & 1.0 & -78 & 15 \\
3 & $\mathrm{NaH}$ & 1.0 & 0 & 7 \\
4 & $\mathrm{Et}{ }_{3} \mathrm{~N}$ & 1.0 & 0 & 7 \\
5 & $\mathrm{MeMgBr}$ & 1.0 & 0 & 60 \\
6 & $\mathrm{MeMgBr}$ & 1.0 & -78 & 79 \\
7 & $\mathrm{MeMgBr}$ & $\mathbf{0 . 9 5}$ & -78 & $86(86)^{b}$ \\
8 & $(n-\mathrm{Bu})_{2} \mathrm{Mg}$ & 0.95 & -78 & 92 \\
\hline
\end{tabular}

${ }^{a}$ Yield on $0.25 \mathrm{mmol}$ scale determined by ${ }^{1} \mathrm{H}$ NMR using 1,3,5-trimethoxybenzene as standard. ${ }^{b}$ Isolated yield in parentheses.

In preliminary scope studies with these methods, we noticed that alkyl Grignard reagents afforded only poor yield of desired addition products and significant decomposition, likely due to their increased basicity (Table 3, entry 1 ). To address this, we imagined that the use of softer organometallic reagents accessible through in situ transmetallation could potentially help solve this issue. For instance, organometallic reagents based on $\mathrm{Ce},{ }^{24} \mathrm{Fe},{ }^{25} \mathrm{Cu},{ }^{26} \mathrm{Ce}^{27} \mathrm{La}^{28}$ and $\mathrm{Zn}^{29}$ are known to smoothly add to enolizable ketones in appropriate conditions. We thus started evaluating different transition metals using benzylmagnesium chloride as reagent, leading to adduct $2 p$ (entries $2-8$ ). While the use of cerium-, copper- or iron-based reagents afforded the product in only low yields (entries 2-4), zinc salts, and particularly mixed Si-stabilized zincates formed using Ishihara's method, ${ }^{29 c}$ led to a good isolated yield of $2 p$ (entry 8 ). 
Table 3. Method C optimization: access to 1-alkylsubstituted cyclopropanols via transmetallation

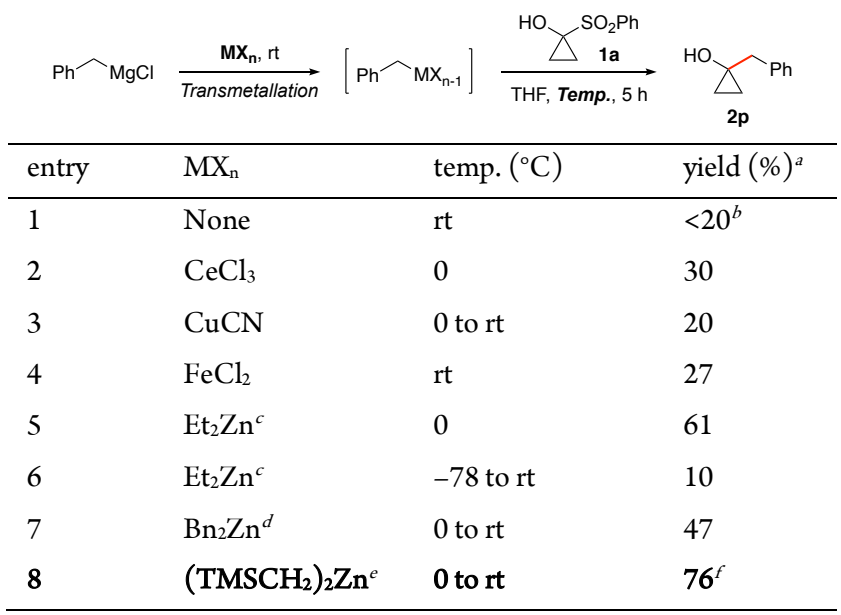

${ }^{a}$ Yield determined by ${ }^{1} \mathrm{H}$ NMR using 1,3,5-trimethoxybenzene as internal standard. ${ }^{b}$ Significant decomposition observed by ${ }^{1} \mathrm{H}$ NMR. ${ }^{\text {SSlow }}$ addition of Grignard reagent via syringe pump. 'Prepared in situ from $\mathrm{Zn}(\mathrm{OMe})_{2}$ (2.2 equiv) and $\mathrm{BnMgCl}\left(2.2\right.$ equiv). ${ }^{29 a}$ eprepared in situ from $\mathrm{ZnCl}_{2}$ (1.2 equiv), $\mathrm{TMSCH}_{2} \mathrm{MgCl}$ (2.4 equiv) and $\mathrm{LiCl}$ (6 equiv) and reaction run for $12 \mathrm{~h}$. Isolated yield.

With these methods in hand and using $\mathbf{1} \mathbf{a}$ as substrate, evaluation of various organometallic nucleophiles revealed an impressive generality for the formation of achiral tertiary cyclopropanols (Scheme 3). Both electron-rich (2a-2c) and electron-poor (2d-2h) para- or metasubstituted arylmagnesium bromides generally afforded good isolated yields of 1-aryl-substituted cyclopropanols. More hindered ortho-substituted reagents were also found to be compatible in the transformation (2i-2l), as well as heteroaryl- (2n) and alkynyl-substituted (2o) nucleophiles. Notably, as the difference between methods A and B is simply the nature of the Grignard reagent effecting the initial deprotonation and no major change in the reaction mechanism is expected, both approaches generally lead to similar efficiency for a given nucleophile. Moreover, method $\mathrm{C}$ proved to be useful for the formation of 1 -alkylcyclopropanols $2 \mathrm{p}$ and $2 \mathrm{q}$ in moderate to good yields.

Our group recently reported a simple approach to optically active substituted 1-sulfonylcyclopropanols, which constitutes the first general enantioselective route to cyclopropanones. ${ }^{22}$ Using this method, chiral substrates $\mathbf{1 b}$ and $\mathbf{1} \mathbf{c}$ were prepared and evaluated in our addition reaction (Scheme 4). Gratifyingly, highly enantioenriched aryl- and vinyl-substituted tertiary cyclopropanols $2 \mathbf{r}-\mathbf{2 t}$ were thus obtained in good to excellent yields using modified method $\mathrm{A}$, affording complete diastereoselectivity for the cis isomer, as evidenced by X-ray analysis of $\mathbf{2 s}$ (Scheme $4 \mathrm{a}) .{ }^{30}$ Employing our modified method $\mathrm{C}$ instead, 1-benzyl-substituted product $2 \mathbf{u}$ could also be obtained in highly enantioenriched form and as a single diastereomer, albeit with some erosion of enantiomeric excess (Scheme $4 b$ ). This partial loss of optical activity is likely a consequence of the use of a zincate as effective nucleophile, where the zinc alkoxide initially formed can equilibrate to its zinc-homoenolate form prior to protonation at the end of the reaction. ${ }^{3,31}$ To the best of our knowledge, these examples constitute the first enantioselective syntheses of cyclopropanols via the addition of nucleophiles to cyclopropanone equivalents.
Scheme 3. Scope of accessible 1-substituted cyclopropanols ${ }^{a}$

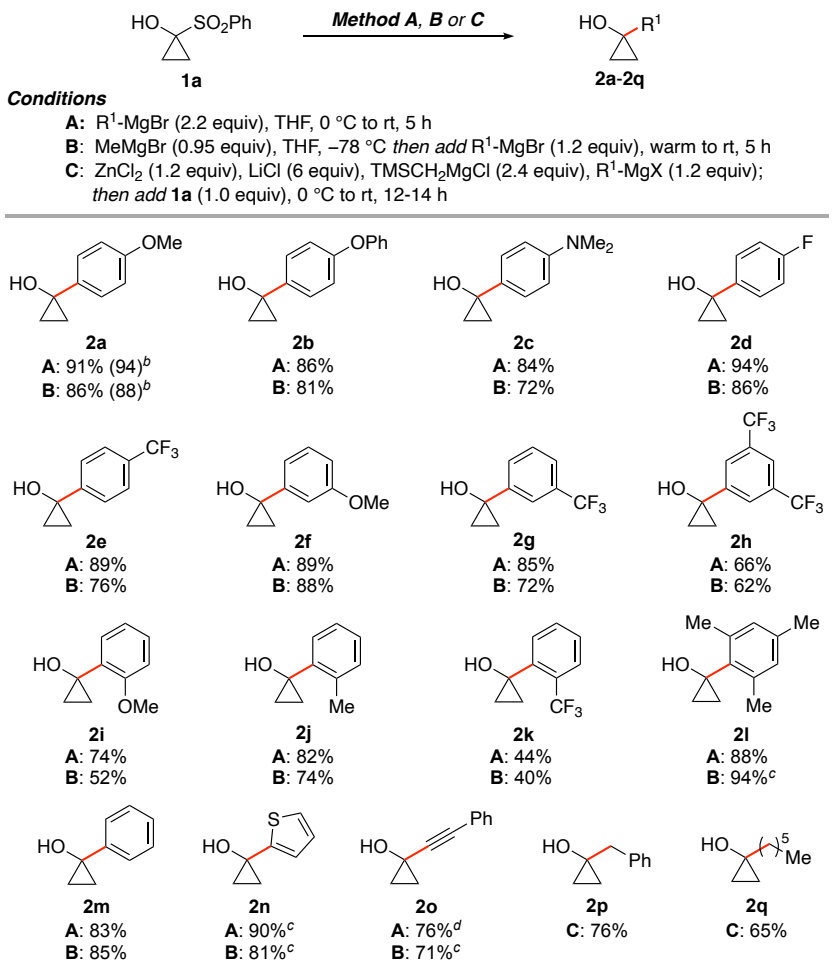

${ }^{a}$ All yields correspond to yields of isolated product on $0.25 \mathrm{mmol}$ scale of 1a unless otherwise noted. ${ }^{b}$ Isolated yield on $2.5 \mathrm{mmol}$ scale of 1a in parentheses. Reaction was stirred at rt for $16 \mathrm{~h}$ instead of $5 \mathrm{~h}$. ${ }^{d}$ Using (phenylethynyl)lithium ( 2.2 equiv), at $-78^{\circ} \mathrm{C}$ to rt.

Scheme 4. Synthesis of enantioenriched 1,2-disubstituted cyclopropanols $^{a, b}$

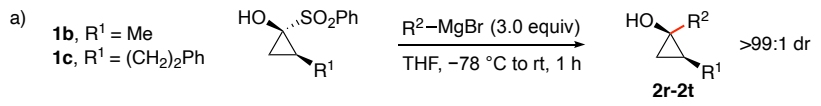

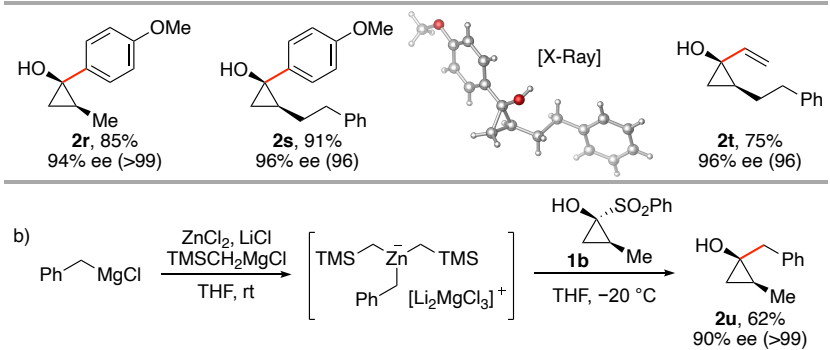

${ }^{a}$ All yields correspond to yields of isolated product on $0.25 \mathrm{mmol}$ scale of $\mathbf{1 b}$ or $\mathbf{1 c}$. ${ }^{b}$ Enantiomeric excesses were determined by HPLC analysis using a chiral stationary phase (ee of starting material $\mathbf{1 b}$ or $\mathbf{1 c}$ in parentheses).

The tertiary cyclopropanols obtained through these methods are known substrates used for further functionalization through homoenolate chemistry, ${ }^{3}$ including sulfonylation, ${ }^{32}$ alkynylation, ${ }^{33}$ halogenation, ${ }^{34}$ cross-coupling, ${ }^{35} \mathrm{C}-\mathrm{H}$ functionalization, ${ }^{36}$ and formal cycloadditions reactions, ${ }^{37}$ all of which typically occur via the corresponding metal alkoxide. Cognizant of this, we envisioned that such $\beta$-functionalized ketones could potentially be obtained in a one-pot, sequential fashion starting from a cyclopropanone surrogate (Scheme 5). As such and using method A, $\gamma$-ketosulfone 4 and $\beta, \gamma$ alkynylketone 5 could thus be obtained directly from substrate 1a 
using known copper-mediated conditions, following addition of $p$ methoxyphenylmagnesium bromide as nucleophile. ${ }^{32,33}$

Scheme 5. One-pot sequential addition and homoenolate $\beta$-functionalization: cyclopropanone as a 3-carbon linchpin ${ }^{a}$

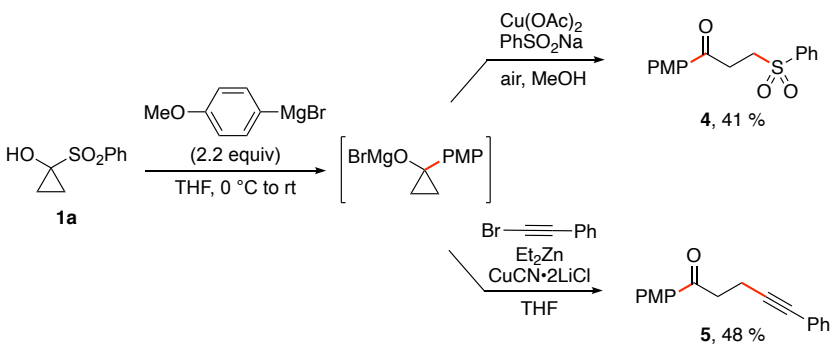

${ }^{a}$ All yields correspond to yields of isolated product directly from 1a (0.25 mmol scale).

In summary, we report a general high-yielding synthesis of tertiary cyclopropanols via the addition of $\mathrm{sp}, \mathrm{sp}^{2}$ or $\mathrm{sp}^{3}$-hybridized organometallic C-nucleophiles to 1-phenylsulfonylcyclopropanol derivatives, acting here as in situ precursors of the corresponding cyclopropanones. A Grignard economy variant using $\mathrm{MeMgBr}$ as external base to initiate the equilibrium to cyclopropanone is also included, and the use of enantioenriched substituted derivatives is shown to afford optically active tertiary cyclopropanols in high yields and complete diastereoselectivity. The addition of other nucleophiles to 1 -sulfonylcyclopropanols as cyclopropanone surrogates and subsequent rearrangements are currently ongoing in our laboratories and will be reported in due course.

\section{ASSOCIATED CONTENT}

(1) For recent reviews on the use of cyclopropanols, see: (a) Haym, I.; Brimble, M. A. Org. Biomol. Chem. 2012, 10, 7649-7665. (b) Ebner, C.; Carreira, E. M. Chem. Rev. 2017, 117, 11651-11679. (c) Cai, X.; Liang, W.; Dai, M. Tetrahedron 2019, 75, 193-208.

(2) For recent reviews on the synthesis of cyclopropanols, see: (a) Kulinkovich, O. G. Chem. Rev. 2003, 103, 2597-2632. (b) Liu, Q.; You, B.; Xie, G.; Wang, X. Org. Biomol. Chem. 2020, 18, 191-204.

(3) For recent reviews on the chemistry of metal-homoenolates, see: (a) Mills, L. R.; Rousseaux, S. A. L. Eur. J. Org. Chem. 2019, 8-26. (b) Nikolaev, A.; Orellana, A. Synthesis 2016, 48, 1741-1768. (c) Rosa, D.; Nikolaev, A.; Nithiy, N.; Orellana, A. Synlett. 2015, 26, 441-448. (d) Nithiy, N.; Rosa, D.; Orellana, A. Synthesis 2013, 45, 3199-3210. (e) Kuwajima, I.; Nakamura, E. In Small Ring Compounds in Organic Synthesis IV; Springer Berlin Heidelberg: 1990, Vol. 155, p 1-39.

(4) Elek, G. Z.; Koppel, K.; Zubrytski, D. M.; Konrad, N.; Järving, I.; Lopp, M.; Kananovich, D. G. Org. Lett. 2019, 21, 8473-8478.

(5) For selected recent examples of the use of tertiary cyclopropanols in total synthesis, see ref. 1c and: (a) Diethelm, S.; Carreira, E. M. J. Am. Chem. Soc. 2015, 137, 6084-6096. (b) Rao, N. N.; Cha, J. K. J. Am. Chem. Soc. 2015, 137, 2243-2246. (c) Rao, N. N.; Parida, B. B.; Cha, J. K. Org. Lett. 2014, 16, 6208-6211. (d) Sethofer, S. G.; Staben, S. T.; Hung, O. Y.; Toste, F. D. Org. Lett. 2008, 10, 4315-4318. (e) Ferrer, S.; Echavarren, A. M. Org. Lett. 2018, 20, 5784-5788. (f) Kim, K.; Cha, J. K. Angew. Chem. Int. Ed. 2009, 48, 5334-5336. (g) Meyer, A. M.; Katz, C. E.; Li, S.-W.; Vander Velde, D.; Aubé, J. Org. Lett. 2010, 12, 1244-1247. (h) Ma, A.-J.; Tu, Y.-Q.; Peng, J.-B.; Dou, Q.-Y.; Hou, S.-H.; Zhang, F.-M.; Wang, S.-H. Org. Lett. 2012, 14, 3604-3607. (i) Mandal, M.; Yun, H.; Dudley, G. B.; Lin, S.; Tan, D. S.; Danishefsky, S. J.J. Org. Chem. 2005, 70, 10619-10637. (j) Davis, D. C.; Walker, K. L.; Hu, C.; Zare, R. N.; Waymouth, R. M.; Dai, M. J. Am. Chem. Soc. 2016, 138, 10693-10699. (k) Ma, K.; Yin, X.; Dai, M. Angew. Chem. Int. Ed. 2018, 57, 15209-15212.

\section{Supporting Information}

Experimental details and spectroscopic data. The Supporting Information is available free of charge on the ACS Publications website. Crystallographic data for compound 2s:

$\mathrm{C}_{18} \mathrm{H}_{20} \mathrm{O}_{2}$ (CIF)

\section{AUTHOR INFORMATION}

Corresponding Author

*Email: vlindsa@ncsu.edu

\section{ORCID}

Roger Machín Rivera: 0000-0002-8635-4568

Vincent N. G. Lindsay: 0000-0002-7126-325X

Notes

The authors declare no competing financial interest.

\section{ACKNOWLEDGMENT}

This work was supported by North Carolina State University startup funds. All X-ray, Nuclear Magnetic Resonance (NMR) and High Resolution Mass Spectrometry (HRMS) measurements were performed by the Molecular Education, Technology, and Research Innovation Center (METRIC) at NC State University, which is supported by the State of North Carolina. We are grateful to Dr. Roger D. Sommer for X-ray analysis of compound 2s. R.M.R. is grateful to NC State University for Diversity Graduate Assistance grants. Y.J. is grateful to NC State University for a Burroughs Wellcome Fellowship in Organic Chemistry. C.M.P. is grateful to NC State University's for a Percy Lavon Julian Award in Organic Chemistry.

\section{REFERENCES}

(6) For syntheses of achiral or racemic secondary cyclopropanols or cyclopropanol itself, see: (a) Magrane, J. K.; Cottle, D. L. J. Am. Chem. Soc. 1942, 64, 484-487. (b) Stahl, G. W.; Cottle, D. L. J. Am. Chem. Soc. 1943, 65, 1782-1783. (c) Roberts, J. D.; Chambers, V. C. J. Am. Chem. Soc. 1951, 73, 3176-3179. (d) Simmons, H. E.; Smith, R. D. J. Am. Chem. Soc. 1959, 81, 4256-4264. (e) DePuy, C. H.; Mahoney, L. R. J. Am. Chem. Soc. 1964, 86, 2653-2657. (f) DePuy, C. H.; Dappen, G. M.; Eilers, K. L.; Klein, R. A. J. Org. Chem. 1964, 29, 2813-2815. (g) Schöllkopf, U. Angew. Chem. Int. Ed. 1968, 7, 588-598. (h) Longone, D. T.; Wright, W. D. Tetrahedron Lett. 1969, 10, 2859-2862. (i) Cheng, K.; Carroll, P. J.; Walsh, P. J. Org. Lett. 2011, 13, 2346-2349.

(7) For selected examples of the synthesis of enantioenriched secondary cyclopropanols, see: (a) Imai, T.; Mineta, H.; Nishida, S. J. Org. Chem. 1990, 55, 4986-4988. (b) Benoit, G.; Charette, A. B. J. Am. Chem. Soc. 2017, 139, 1364-1367. (c) Simaan, M.; Marek, I. Angew. Chem. Int. Ed. 2018, 57, 1543-1546. (d) Simaan, M.; Marek, I. Beilstein J. Org. Chem. 2019, 15, 752 760.

(8) (a) Imamoto, T.; Kamiya, Y.; Hatajima, T.; Takahashi, H. Tetrahedron Lett. 1989, 30, 5149-5152. (b) Ito, S.; Shinokubo, H.; Oshima, K. Tetrahedron Lett. 1998, 39, 5253-5256 (c) Barluenga, J.; Suero, M. G.; PérezSánchez, I.; Flórez, J. J. Am. Chem. Soc. 2008, 130, 2708-2709.

(9) For a rare example of the enantioselective cyclopropanation of silyl enol ethers leading to enantioenriched tertiary cyclopropanols, see: Du, H.; Long, J.; Shi, Y. Org. Lett. 2006, 8, 2827-2829.

(10) (a) Kulinkovich, O. G.; Sviridov, S. V.; Vasilevski, D. A.; Pritytskaya, T. S. Russ J. Org. Chem. 1989, 25, 2027-2028. (b) Kulinkovich, O. G.; Vasilevskii, D. A.; Savchenko, A. I.; Sviridov, S. V. Russ.J. Org. Chem. 1991, 27, 1249-1251 (c) Kulinkovich, O. G.; Sviridov, S., V.; Vasilevski, D. A. Synthesis 1991, 234. 
(11) For reviews, see: (a) Kulinkovich, O. G.; de Meijere, A. Chem. Rev. 2000, 100, 2789-2834. (b) Kulinkovich, O. G. Russ. Chem. Bull. 2004, 53, 1065-1086. (c) Kulinkovich, O.; Isakov, V.; Kananovich, D. Chem. Rec. 2008, 8, 269-278. (d) Cha, J. K.; Kulinkovich, O. G. Org. React. 2012, 77, 1 159. (e) Konik, Y. A.; Kananovich, D. G. Tetrahedron Lett. 2020, 61, 152036.

(12) For rare examples of asymmetric Kulinkovich cyclopropanation reactions, see: (a) Corey, E. J.; Rao, S. A.; Noe, M. C. J. Am. Chem. Soc. 1994, 116, 9345-9346. (b) Konik, Y, A.; Kananovich, D. G.; Kulinkovich, O. G. Tetrahedron 2013, 69, 6673-6678. (c) Kulinkovich, O. G.; Kanakovich, D. G.; Lopp, M.; Snieckus, V. Adv. Synth. Catal. 2014, 356, 3615-3626. (d) Iskryk, M.; Barysevich, M.; Oseka, M.; Adamson, J.; Kananovich, D. Synthesis $2019,51, \mathrm{~A}-\mathrm{N}$.

(13) For other approaches leading to racemic tertiary cyclopropanols, see: (a) Trost, B. M.; Bogdanowicz, M. J. J. Am. Chem. Soc. 1973, 95, 289 290. (b) Trost, B. M.; Bogdanowicz, M. J. J. Am. Chem. Soc. 1973, 95, 5311 5321. (c) Hussain, M. M.; Li, H.; Hussain, N.; Ureña, M.; Carroll, P. J.; Walsh, P. J.J. Am. Chem. Soc. 2009, 131, 6516-6524. (d) Ukai, K.; Oshima, K.; Matsubara, S. J. Am. Chem. Soc. 2000, 122, 12047-12048. (e) Matsubara, S.; Ukai, K.; Fushimi, H.; Yokota, Y.; Yoshino, H.; Oshima, K.; Omoto, K.; Ogawa, A.; Hioki, Y.; Fujimoto, H. Tetrahedron 2002, 58, 8255-8262.

(14) (a) Wasserman, H. H.; Clagett, D. C. Tetrahedron Lett. 1964, 5 , 341-344. (b) Wasserman, H. H.; Clagett, D. C. J. Am. Chem. Soc. 1966, 88, 5368-5369. (c) Wasserman, H. H.; Cochoy, R. E.; Baird, M. S. J. Am. Chem. Soc. 1969, 91, 2375-2376.

(15) For related examples, see: (a) Brown, H. C.; Rao, C. G. J. Org. Chem. 1978, 43, 3602-3604. (b) Salaun, J.; Bennani, F.; Compain, J. C.; Fadel, A.; Ollivier, J. J. Org. Chem. 1980, 45, 4129-4135. (c) Wasserman, H. H.; Hearn, M. J.; Cochoy, R. E. J. Org. Chem. 1980, 45, 2874-2880.

(16) For rare and specific examples of the synthesis of an enantioenriched, methyl-substituted hemiketal used as cyclopropanone equivalent, see: (a) Nakamura, E.; Sekiya, K.; Kuwajima, I. Tetrahedron Lett. 1987, 28, 337-340. (b) Fadel, A.; Canet, J.-L.; Salaün, J. Synlett 1990, 89-91. (c) Fadel, A.; Khesrani, A. Tetrahedron: Asymmetry 1998, 9, 305-320. (d) Fadel, A.; Tesson, N. Eur.J. Org. Chem. 2000, 2153-2159.

(17) Nakamura, E.; Kuwajima, I. J. Am. Chem. Soc. 1977, 99, 7360-7362.

(18) (a) Dudev, T.; Lim, C. J. Am. Chem. Soc. 1998, 120, 4450-4458. (b) Bach, R. D.; Dmitrenko, O. J. Am. Chem. Soc. 2006, 128, 4598-4611. (c) Liebman, J. F.; Greenberg, A. Chem. Rev. 1976, 76, 311-365. (d) Liebman, J. F.; Greenberg, A. Chem. Rev. 1989, 89, 1225-1246.

(19) (a) Turro, N. J.; Hammond, W. B. J. Am. Chem. Soc. 1966, 88, 3672 3673. (b) van Tilborg, W. J. M.; Steinberg, H.; de Boer, T. J. Synth. Commun. 1973, 3, 189-196. (c) De Kimpe, N. Cyclopropanone. In Encyclopedia of Reagents for Organic Synthesis; Charette, A.B.; Crich, D.; Fuchs, P. L., Eds.; John Wiley \& Sons Ltd, Chichester, 2nd edn, 2001.

(20) For reviews on the synthesis and applications of cyclopropanone derivatives, see: (a) Turro, N. J. Acc. Chem. Res. 1969, 2, 25-32. (b) Wasserman, H. H.; Clark, G. M.; Turley, P. C. In Stereochemistry I; Springer Berlin Heidelberg: 1974; Vol. 47, p 73-156. (c) Wasserman, H. H.; Berdahl, D. R.; Lu, T.-J. In The Chemistry of the Cyclopropyl Group; Rappoport, Z., Ed.; Chichester ; New York : Wiley, 1987; pp 1455-1532. (d) Salaun, J. Chem. Rev. 1983, 83, 619-632. (e) Regnier, V.; Martin, D. Org. Chem. Front. 2015, 2, 1536-1545.

(21) (a) Liu, J.; An, Y.; Jiang, H.-Y.; Chen, Z. Tetrahedron Lett. 2008, 49, 490-494. For other transformations using 1-sulfonylcyclopropanols as cyclopropanone precursors, see: (b) An, Y.; Liu, J.; Jiang, H.-Y.; Wang, Y.; Chen,
Z. Tetrahedron Lett. 2008, 49, 3124-3128. (c) Liu, J.; An, Y.; Wang, Y.-H.; Jiang, H.-Y.; Zhang, Y.-X.; Chen, Z. Chem. Eur. J. 2008, 14, 9131-9134. (d) Zhang, Y.-X.; Guo, L.; Wang, Y.-H.; Zhu, L.-L.; Chen, Z.-L. Synth. React. Inorg. M. 2010, 40, 241-245.

(22) Poteat, C. M.; Jang, Y.; Jung, M.; Johnson, J. D.; Williams, R. G.; Lindsay, V. N. G. Angew. Chem. Int. Ed. 2020, DOI: 10.1002/anie.202006786.

(23) THF was chosen for the remaining of the investigation in view of developing a general method compatible with most organometallic reagents, some of which are known to have solubility issues in $t$-BuOMe.

(24) (a) Imamoto, T.; Takiyama, N.; Nakamura, K. Tetrahedron Lett. 1985, 26, 4763-4766. (b) Imamoto, T.; Takiyama, N.; Nakamura, K.; Hatajima, T.; Kamiya, Y. J. Am. Chem. Soc. 1989, 111, 4392-4398. (c) Bartoli, G.; Marcantoni, E.; Petrini, M. J. Chem. Soc. Chem. Commun. 1993, 13731374.

(25) Mutsumi, S.; Seijiro, M. Chem. Lett. 2008, 37, 800-801.

(26) (a) Bertz, S. H.; Eriksson, M.; Miao, G.; Snyder, J. P. J. Am. Chem. Soc. 1996, 118, 10906-10907. (b) Posner, G. H., Org. React. 2011, 19, 1 113.

(27) Imamoto, T.; Sugiura, Y.; Takiyama, N. Tetrahedron Lett. 1984, 25, 4233-4236.

(28) Krasovskiy, A.; Kopp, F.; Knochel, P. Angew. Chem. Int. Ed. 2006, $45,497-500$

(29) (a) Côté, A.; Charette, A. B. J. Am. Chem. Soc. 2008, 130, 2771 2773. (b) Hatano, M.; Ito, O.; Suzuki, S.; Ishihara, K. Chem. Commun. 2010, 46, 2674-2676. (c) Hatano, M.; Ito, O.; Suzuki, S.; Ishihara, K. J. Org. Chem. 2010, 75, 5008-5016.

(30) CCDC 2015376 (2s) contains the supplementary crystallographic data for this paper. These data can be obtained free of charge from The Cambridge Crystallographic Data Centre via www.ccdc.cam.ac.uk/structures.

(31) Nickon, A.; Lambert, J. L. S. J. J. Am. Chem. Soc. 1962, 84, 4604 4605 .

(32) Konik, Y. A.; Elek, G. Z.; Kaabel, S.; Järving, I.; Lopp, M.; Kananovich, D. G. Org. Biomol. Chem. 2017, 15, 8334-8340.

(33) Murali, R. V.; Rao, N. N.; Cha, J. K. Org. Lett. 2015, 17, 3854-3856.

(34) (a) Zhao, H.; Fan, X.; Yu, J.; Zhu, C. J. Am. Chem. Soc. 2015, 137, 3490-3493. (b) Ren, S.; Feng, C.; Loh, T.-P. Org. Biomol. Chem. 2015, 13, 5105-5109. (c) Ishida, N.; Okumura, S.; Nakanishi, Y.; Murakami, M. Chem. Lett. 2015, 44, 821-823. (d) Allen, B. D. W.; Hareram, M. D.; Seastram, A. C.; McBride, T.; Wirth, T.; Browne, D. L.; Morrill, L. C. Org. Lett. 2019, 21, 9241-9246.

(35) (a) Rosa, D.; Orellana, A. Chem. Commun. 2013, 49, 5420-5422. (b) Nikolaev, A.; Nithiy, N.; Orellana, A. Synlett. 2014, 25, 2301-2305. (c) Rosa, D.; Orellana, A. Org. Lett. 2011, 13, 110-113. (d) Parida, B. B.; Das, P. P.; Niocel, M.; Cha, J. K. Org. Lett. 2013, 15, 1780-1783. (e) Nithiy, N.; Orellana, A. Org. Lett. 2014, 16, 5854-5857. (f) Ye, Z.; Cai, X.; Li, J.; Dai, M. ACS Catal. 2018, 8, 5907-5914.

(36) (a) Ilangovan, A.; Saravanakumar, S.; Malayappasamy, S. Org. Lett. 2013, 15, 4968-4971. (b) Nikolaev, A.; Legault, C. Y.; Zhang, M.; Orellana, A. Org. Lett. 2018, 20, 796-799.

(37) (a) Yang, J.; Sun, Q.; Yoshikai, N. ACS Catal. 2019, 9, 1973-1978. (b) Wang, Y.-F.; Toh, K. K.; Ng, E. P. J.; Chiba, S. J. Am. Chem. Soc. 2011, $133,6411-6421$ 